\title{
Occurrence of Pseudomonas aeruginosa in Kuwait environment
}

\author{
A. Akbar, D. AL-Otaibi, H. Drobiova, C. Obwekue \& E. Al-Saleh \\ Microbiology Program, Department of Biological Sciences, \\ P.O. Box 5969, Safat 13060, College of Science, \\ Kuwait University, State of Kuwait
}

\begin{abstract}
Deliberate and accidental releases of opportunistic pathogens such as Pseudomonas aeruginosa into the environment increase the likelihood of spreading infectious diseases. Also, $P$. aeruginosa is responsible for nosocomial infections and usually harbour several antibiotic resistance genes. In the present study total of 76 strains of $P$. aeruginosa were characterized (54 strains were isolated from soil samples collected from a crude oil contaminated site located north of Kuwait and 22 strains were isolated from medical samples). Whereas the phenotypic characterization such as the biochemical tests using VITEK 2 system (bioMérieux) and antibiotics susceptibility testing (AST) showed the high similarity between the medical and the environmental strains, the molecular analyses based on multilocus sequence typing (MLST) and restriction fragment length polymorphism (RFLP) demonstrated the heterogeneity of isolated $P$. aeruginosa indicating the presence of different clusters. Comparison of fingerprints obtained, confirmed the negative correlation between the environmental and the medical strains. In addition, results demonstrated that environmental strains are better adapted to crude oil contaminated sites. However, environmental strains may represent hidden reservoirs for pathogenic traits that may disseminate to other bacteria in the environment.
\end{abstract}

Keywords: Pseudomonas aeruginosa; pathogenicity; MLST; RFLP; phenotype; antibiotic.

\section{Introduction}

The versatile and ubiquitous bacterium Pseudomonas aeruginosa is one of the most important opportunistic pathogens that can affect a wide variety of 
organisms, such as insects, nematodes, plants, birds, and mammals including humans (Pukatzki et al., [1]; Jander et al., [2]). Pseudomonas aeruginosa can cause infections in immuno-compromised patients suffering from burns, or with underlying diseases such as cystic fibrosis, cancer or AIDS (Doring, [3]). Nevertheless, $P$. aeruginosa also affects healthy individuals and is an etiological agent to consider in the differential diagnosis of rapidly progressing diseases such as community-acquired pneumonia (McCallum, [4]). Furthermore, $P$. aeruginosa has low antibiotic susceptibility attributed to the presence of antibiotic resistance. Acquired resistance to antibiotics can also be developed by either mutation or the horizontal gene transfer of antibiotic resistance determinants (Livermore, [5]).

Environmental strains of $P$. aeruginosa can degrade environmental pollutants and can be bioaugmented in contaminated soils as a strategy in bioremediation programs to treat crude oil contaminated sites. The presence of $P$. aeruginosa in large numbers in the environment may represent a putative risk to wild life (Garnica and Vives-Flórez, [6]) and to people who might unsuspectingly be in direct contact with the environment.

In 1991 after the Gulf War over 300 oil lakes formed in the Kuwait desert. The bulk volume of the oil-contaminated soils has been estimated as 18 million cubic meter (Readman et al., [7]) that created selection pressure for crude oildegrading bacteria in contaminated soils resulting in high occurrence of crude oil-degraders such as $P$. aeruginosa. Consequently, the high spread of such opportunistic bacteria in the environment of Kuwait increases the probability of spreading infectious diseases.

In this study, differences between the environmental and medical $P$. aeruginosa strains were determined using biochemical tests and antibiotic susceptibility testing (AST). Furthermore, genotyping of isolated bacteria using multilocus sequence typing (MLST) and restriction fragment length polymorphism (RFLP) were used to distinguish between different strains of $P$. aeruginosa.

\section{Materials and methods}

\subsection{Isolation of $P$. aeruginosa}

Some P.aeruginosa isolates were collected from microbiology laboratories in hospitals in Kuwait. Environmental P. aeruginosa strains were isolated from crude oil contaminated soil samples by standard plate dilution technique. Soil samples $(1 \mathrm{~g})$ were mixed with of Hutners media $(50 \mathrm{ml})$, shaken for 1 hour and the resulting suspension was allowed to settle for $30 \mathrm{~min}$. The supernatant was serially diluted and spread $(0.1 \mathrm{ml})$ on Hutners minimal agar plates, incubated in presence of crude oil at $25^{\circ} \mathrm{C}$ for 14-21 days. Grown colonies were re-streaked on nutrient agar plates (NA). Pure cultures grown on NA plates were used for biochemical tests, antibiotic susceptibility testing (AST) and DNA extraction. The biochemical tests and AST were conducted using the VitechII (bioMérieux) following the manufacturer's instructions. 


\subsection{Identification of bacteria using 16S rDNA sequencing}

Genomic DNA was purified from pure bacterial cultures using the Wizard Genomic DNA purification kit as recommended by the manufacturer's (Promega). Then, the 16S rRNA gene was amplified using polymerase chain reaction (PCR). Amplification was performed using puReTaq Ready to Go PCR beads (Amersham Biosciences) according to manufacturer's recommendations, 200 pmol of mixture of the two primers used $27 \mathrm{~F}$ (5'CUACUACUACUAAAGGAGGTGWTCCARCC-3') and 1492R (5'GAATTCTACGGYTACCTTGTTACGACTT-3') was added. The reactions were amplified using (GeneAmp PCR system 9700, Applied Biosystem). The PCR program used was a touchdown protocol that started with an initial denaturation step at $94^{\circ} \mathrm{C}$ for $5 \mathrm{~min}$, followed by a denaturation step at $94^{\circ} \mathrm{C} 45 \mathrm{~s}$, annealing step at $56^{\circ} \mathrm{C}$ for $45 \mathrm{~s}$, and an extension step at $72^{\circ} \mathrm{C}$ for $1 \mathrm{~min}$. Annealing temperature was decreased by $2^{\circ} \mathrm{C}$ each 6 cycles for a total of 30 cycles. A final extension step was carried at $72^{\circ} \mathrm{C}$ for $7 \mathrm{~min}$. Products were analyzed by gel electrophoresis where $5 \mu \mathrm{l}$ of each samples was run on $0.5 \%$ $(\mathrm{w} / \mathrm{v})$ agarose gel along with $1 \mathrm{~kb}$ DNA ladder.

The PCR products obtained were purified using a Nucleospin Extract II kit (Macherey-Nagel, USA). The purified products were amplified using big dye terminator cycle sequencing kit according to manufacturer's instructions. The mixtures were incubated in the thermocycler at $96^{\circ} \mathrm{C}$ for 1 minute followed by 25 cycles of denaturation at $96^{\circ} \mathrm{C}$ for 1 minute, annealing at $50^{\circ} \mathrm{C}$ for $5 \mathrm{~s}$ and extension at $60^{\circ} \mathrm{C}$ for 4 minutes. The final products were further purified, using $3 \mu \mathrm{l}$ of $3 \mathrm{M}$ sodium acetate $\mathrm{pH} 4.6,62.5 \mu \mathrm{l}$ of nondenatured $95 \%$ ethanol and 14.5 $\mu 1$ of deionized water. Samples were incubated in the dark at room temperature for 20 minutes before being centrifuged at $15,000 \mathrm{xg}$ in room temperature for 20 minutes. The pellet formed was washed with $250 \mu \mathrm{l}$ of $70 \%$ ethanol and recentrifuged at $15,000 \mathrm{xg}$ in room temperature for 5 minutes. The pellets were airdried for 10-15 minutes, re-suspended in $20 \mu \mathrm{l}$ of Hi-Di-Formamide and loaded directly in the 3130xl genetic analyzer (Applied Biosystems). Sequence analysis and GeneBank database searches were performed by using the BLAST program (Altschul et al., [8]).

\subsection{Multilocus sequence typing (MLST)}

Multilocus sequence typing (MLST) was performed as proposed by (Curran et al., [9]). Seven internal fragments of the genes acsA, aroE, guaA, mutL, nuoD, pps $A$, and $\operatorname{trpE}$ were amplified, and the resulting PCR products were purified with the Nucleospin ${ }^{\circledR}$ Extract II kit (Macherey-Nagel, USA). PCR Sequencing was carried out with sequencing primers by the 3130xl genetic analyzer (Applied Biosystems, USA). The database at http://pubmlst.org was used to assign numbers to particular alleles and to identify sequence types (STs). 


\subsection{RFLP analysis of $16 \mathrm{~S}$ rDNA}

16S rDNA sequences of cultured isolates were amplified directly from glycerol stock using M13 vector-specific primers. Each $50-\mu 1$ reaction mixture contained $30 \mathrm{mM}$ Tris ( $\mathrm{pH} 8.4$ ), $50 \mathrm{mM} \mathrm{KCl}, 1.5 \mathrm{mM} \mathrm{MgCl}_{2}$, each deoxynucleoside triphosphate will be at a concentration of $50 \mu \mathrm{M}$, with $50 \mathrm{pmol}$ of each primer, and 1.9 U of Taq polymerase (AmpliTaq; Applied Biosystems). Following PCR amplification of $16 \mathrm{~S}$ sequences, $10 \mu \mathrm{l}$ of PCR products were digested separately with $2.5 \mathrm{U}$ of $R s a \mathrm{I}$ or $2.5 \mathrm{U}$ of $B s t \mathrm{UI}$ (New England Biolabs) in 12- $\mu$ l reaction mixtures as recommended by the manufacturer. $R s a \mathrm{I}$ and $B s t \mathrm{UI}$ digests were electrophoresed in $2 \%$ agarose gels, with TBE buffer. The gels were stained with ethidium bromide and photographed under UV light using InGenius gel documentation system (Syngene, Inc.). DNA fragment sizes were determined using GeneTools analysis software (Syngene, Inc.). The quality of the numerical data was checked by comparing the sum of fragment sizes in each restriction pattern with the original product size (approximately 1,499 bp). Cluster analysis of band patterns was carried out using GelComparII software (Applied Maths). Each phylotype was defined as a group of sequences that have indistinguishable $R s a \mathrm{I}$ and $B s t \mathrm{UI}$ restriction patterns.

\subsection{Mineralization of crude oil by bacteria}

The amounts of carbon dioxide evolved were measured using a Micro-oxymax respirometer (Columbus instruments, USA). The reaction bottles contain: $49 \mathrm{ml}$ sterile Hunter's minimal medium, crude oil $(200 \mu \mathrm{l})$ and $1 \mathrm{ml}$ of overnight bacterial suspension (OD $=1$ at $\lambda 600 \mathrm{~nm}$ ). The reaction bottles were incubated shaking at $30^{\circ} \mathrm{C}$. The amount of carbon dioxide evolved was plotted against time and the rate of carbon dioxide evolution was calculated and used as indication for crude oil mineralization.

\section{Results and discussion}

The biochemical characterization of isolated bacteria showed the high similarity between the environmental and the medical strains. In addition, the AST data revealed the high similarity in the reaction of bacteria to antibiotics used. However, the medical strains showed wider range of resistance to three antibiotics (Table 1). While all environmental strains were sensitive to cefepime, $65 \%$ of medical strains were resistant to this antibiotic. Furthermore, $85 \%$ of medical strains were resistant to ceftazidime compared to $6 \%$ of that of environmental strains. Also, $50 \%$ of the medical strains were resistant to piperacillin/Tazobactam in contrast to $4 \%$ resistance demonstrated by the environmental strains. The resistance to wider range of antibiotics demonstrated by the medical strains is expected and can be attributed to the potential of bacteria to acquire resistance to antibiotics especially under frequent encounter with antibiotics in hospitals (Okeke et al., [10]). 
Table 1: $\quad$ Antibiotic susceptibility test of isolated P. aeruginosa.

\begin{tabular}{cc}
\hline \multicolumn{1}{c}{ Antibiotic } & AST \\
\hline $\begin{array}{c}\text { Amikasin, Piperacillin, Tobramycin, Ciprofloxacin, Gentamicin } \\
\text { Ampicillin, Amoxicillin } \backslash \text { clavulanic acid, Cefalotin, Cefotaxime, } \\
\text { Cefoxitin, Cefpodoxime, Nitrofurantoin, } \\
\text { Trimethoprim } \text { Sulfamethoxazole }\end{array}$ & $\mathrm{S}$ \\
& $\mathrm{R}$ \\
Cefepime & $\begin{array}{l}65 \% \text { of medical } \\
\text { strains are R, all } \\
\text { environmental } \\
\text { strains are } \mathrm{S}\end{array}$ \\
& $\begin{array}{l}85 \% \text { of medical } \\
\text { strains are } \mathrm{R}, 6 \% \\
\text { of environmental } \\
\text { strains are } \mathrm{R}\end{array}$ \\
& $\begin{array}{l}50 \% \text { of medical } \\
\text { strains are } \mathrm{R}, 4 \%\end{array}$ \\
& $\begin{array}{l}\text { of environmental } \\
\text { strains are } \mathrm{R}\end{array}$ \\
\hline
\end{tabular}

AST= antibiotic susceptibility testing; $\mathrm{S}=$ sensitive; $\mathrm{R}=$ resistant.

Whereas the phenotypic characterization using biochemical tests and AST demonstrated the high similarity between the medical and the environmental strains, the molecular analyses based on MLST and RFLP revealed the heterogeneity of isolated $P$. aeruginosa as demonstrated by the presence of different sequence types and clusters. MLST fingerprints showed that the medical and the environmental strains were assigned to different sequence types and thus probably belong to different phylotypes (Table 2). The environmental strains were grouped into two phylotypes (with ST of 408 and 219) and the medical strains were grouped into twelve phylotypes. This indicated the distinct evolutionary origins of the two groups of tested bacteria and the higher heterogeneity of the medical strains compared to the environmental strains. Other studies have demonstrated the potential of MLST approach to determined genetic relatedness among different clones of the same bacterium (Curran et al., [9]). However, 16S-RFLP fingerprints showed that isolated bacteria were grouped into five distinctive phylotypes (Table 3). Except for group four which comprised of environmental strains, the majority (88-77\%) of other groups (group 1, 2, 3 and 5) was formed by either environmental (group 2 and 5) or medical (group 1 and 3) strains. Thus, MLST and RFLP methods suggest that the environmental and the medical strains were not closely related. This may suggest that infections caused by $P$. aeruginosa were probably due to bacterial strains acquired by patients subsequent to hospital admission but not from the environment as confirmed from patient's history that indicated the infections 
Table 2: $\quad$ Multilocus sequence typing of isolated $P$. aeruginosa.

\begin{tabular}{ccc}
\hline P. aeruginosa strain & $\begin{array}{c}\text { Source of } \\
\text { strains }\end{array}$ & STs \\
\hline SK27, SK 31, SK 39, SK 44, SK 52, SK 60, SK 61, SK 90, & $\begin{array}{c}\text { Crude oil } \\
\text { contaminated } \\
\text { soil }\end{array}$ & 408 \\
SK 4, SK 8, SK17, SK 63, SK 64, SK 66, SK 68, SK 69 & & 219 \\
\hline Ps 1 & & 250 \\
Ps 4 & & 320 \\
Ps 5 & & 506 \\
Ps 6 & Medical & 106 \\
Ps 7 & hospitals & 387 \\
Ps 9 & & 357 \\
Ps17 & & 447 \\
Ps 18 & & 313 \\
Ps 11, Ps 2 & & 316 \\
Ps 22, Ps 15 & & 511 \\
Ps 20 & & 325 \\
Ps 24 & & \\
\hline
\end{tabular}

Table 3: $\quad$ Restriction fragment length polymorphism analysis of isolated P. aeruginosa.

\begin{tabular}{|c|c|c|}
\hline Phylotype & Environmental strains & Medical strains \\
\hline 1 & $\begin{array}{c}1) \\
\text { SK2 }\end{array}$ & $\begin{array}{l}\text { (5) } \\
\text { Ps2, Ps3, Ps8, Ps9, } \\
\text { Ps12 }\end{array}$ \\
\hline 2 & $\begin{array}{c}(8) \\
\text { SK1, SK24, SK27, SK29, SK68, SK70, SK71, } \\
\text { SK75 }\end{array}$ & $\begin{array}{c}(1) \\
\text { Ps14 }\end{array}$ \\
\hline 3 & $\begin{array}{c}(3) \\
\text { SK72, SK89, SK90 }\end{array}$ & $\begin{array}{l}\text { (15) } \\
\text { Ps15, Ps16, Ps17, } \\
\text { Ps20, Ps21, Ps1, } \\
\text { Ps11, Ps10, Ps2, } \\
\text { Ps4, Ps5, Ps6, Ps7 }\end{array}$ \\
\hline 4 & $\begin{array}{c}\text { (35) } \\
\text { SK39, SK47, SK44, SK41, SK52, SK50, SK53, } \\
\text { SK58, SK60, SK48, SK61, SK22, SK64, SK35, } \\
\text { SK38, SK6, SK34, SK21, SK88, SK91, SK69, } \\
\text { SK76, SK78, SK66, SK82, SK84, SK86, SK67, } \\
\text { SK87, SK79, SK63, SK73, SK65, SK31, SK77 }\end{array}$ & (2) \\
\hline 5 & SK19, SK17, SK20, SK8, SK11, SK12, SK4 & $\begin{array}{c}(1) \\
\text { Ps19 }\end{array}$ \\
\hline
\end{tabular}

Numbers between brackets indicate the number of strains included in a particular group. 
were nosocomial. Nonetheless, more bacteria must be tested with several techniques to reach such conclusion.

The crude oil mineralization studies demonstrated that all the environmental strains were able to utilize crude oil as sole carbon and energy source. Other studies indicated that, pathogenic bacteria such as $P$. aeruginosa able to utilize crude oil can be isolated from the environment (Chaerun et al., [11]; Hasanuzzaman et al., [12]). However, none of the medical strains grew in the presence of crude oil. Hence, results demonstrated that environmental strains are better adapted to crude oil contaminated sites.

The high virulence of $P$. aeruginosa warrant more investigations to elucidate the relation between the environmental and the medical strains in order to reveal the points of release of pathogenic bacteria into the environment. The environmental strains may be better adapted to stress conditions such as crude oil pollution but may represent hidden reservoirs for pathogenic traits that may disseminate to other bacteria in the environment.

\section{References}

[1] Pukatzki, S., Kessin, R.H. \& Mekalanos, J.J., The human pathogen Pseudomonas aeruginosa utilizes conserved virulence pathways to infect the social amoeba Dictyostelium discoideum. Proceedings of the National Academy of Sciences of the United States of America. 99(5), pp. 31593164, 2002.

[2] Jander, G., Rahme, L.G. \& Ausubel, F.M., Positive correlation between virulence of Pseudomonas aeruginosa mutants in mice and insects. Journal of Bacteriology, 182(13), pp. 3843-3845, 2000.

[3] Doring, D., Chronic Pseudomonas aeruginosa lung infection in cystic fibrosis patients. In Pseudomonas aeruginosa as an opportunistic pathogen New York: Plenum Press; pp. 245-273, 1993.

[4] McCallum, S.J., Gallagher, M.J., Corkill, J.E., Hart, C.A., Ledson, M.J. \& Walshaw, M.J., Spread of an epidemic Pseudomonas aeruginosa strain from a patient with cystic fibrosis (CF) to non-CF relatives. Thorax, 57(6), pp. 559-560, 2002.

[5] Livermore, D.M., Multiple mechanisms of antimicrobial resistance in Pseudomonas aeruginosa: our worst nightmare? Clinical infectious diseases, 34(5), pp. 634-640, 2002.

[6] Garnica, D. \& Vives-Florez, M., Comparison of virulence between clinical and environmental Pseudomonas aeruginosa isolates. International Microbiology, 9(4), pp. 247-252, 2006.

[7] Readman, J. W., Bartocci, J., Tolosa, I., Fowler, S.W., Oregioni, B. \& Abdulraheem, M.Y., Recovery of the coastal marine environment in the Gulf following the 1991 war-related oil spills. Marine Pollution Bulletin, 32(6), pp. 493-498, 1996.

[8] Altschul, S.F., Madden, T.L., Schäffer, A.A., Zhang, J., Zhang, Z., Miller, W. \& Lipman DJ., Gapped BLAST and PSI-BLAST: a new generation of 
protein database search programs. Nucleic acid research, 25(17), pp. 33893402, 1997.

[9] Curran, B., Jonas, D., Grundmann, H., Pitt, T. \& Dowson, C.G., Development of a Multilocus Sequence Typing Scheme for the Opportunistic Pathogen Pseudomonas aeruginosa. Journal of clinical microbiology, 42(12), pp. 5644-5649, 2004.

[10] Okeke, I.N., Lamikanra A. \& Edelman, R., Socioeconomic and Behavioral Factors Leading to Acquired Bacterial Resistance to Antibiotics in Developing Countries. Emerging Infectious Diseases, 5(1), pp. 18-27, 1999.

[11] Chaerun, S.K., Tazaki, K., Asada, R. \& Kogure, K., Bioremediation of coastal areas 5 years after the Nakhodka oil spill in the Sea of Japan: isolation and characterization of hydrocarbon-degrading bacteria. Environment International, 30(7), pp. 911-922, 2004.

[12] Hasanuzzaman, M., Umadhay-Briones, K.M., Zsiros, S.M., Morita, N., Nodasaka, Y. \& Okuyama, I. H., Isolation, identification and characterization of a novel, oil-degrading bacterium, Pseudomonas aeruginosa T1. Current Microbiology Isolation, 49(2), pp. 108-114, 2004. 